\title{
Mechanical Properties and Microstructures of As Printed and Heat Treated Samples of Selective Laser Melted IN625 Alloy Powder
}

\author{
Raghavan Srinivasan ${ }^{1, a}$, SunChen-Nan ${ }^{1, b}$, Zhang Baicheng ${ }^{1, c}$, Sin Wai Jack ${ }^{1, d}$, \\ Wang Pei ${ }^{2, e}$, Nai Mui Ling Sharon ${ }^{1, f}$, Li Tao ${ }^{1, g}$, Wei Jun ${ }^{1, h}$ \\ ${ }^{1}$ Singapore Institute of Manufacturing Technology (SIMTech), 71 Nanyang Drive, Singapore 638075 \\ ${ }^{2}$ Institute of Materials Research and Engineering (IMRE), 3 Research Link, Singapore 117602
}

\begin{abstract}
The current study focusses in evaluating the mechanical properties (yield strength, ultimate tensile strength and elongation \%) and microstructures of as printed and heat treated tensile samples produced by Selective Laser Melting (SLM) which is an Additive Manufacturing (AM) technique. The as printed IN625 alloy exhibited good mechanical properties as compared to cast and wrought alloy, owing to fast cooling rates that give very fine dendritic/cellular structures during the SLM process. Standard solutionizing and precipitation hardening treatment was given to the SLM as printed samples. The as printed sample's ductility increased from $30 \%$ elongation to $47 \%$ elongation with small drop in tensile strength from $878 \mathrm{MPa}$ to $836 \mathrm{MPa}$. The increase of ductility after heat treatment was evident in the change of fracture morphology from long straight striations with dimple shape ductile like features in the as printed sample to mainly dimple shaped ductile-like fracture surface in the heat treated sample as observed in the FESEM.
\end{abstract}

\section{Introduction}

Additive Manufacturing (AM) techniques apply the addition of material layer by layer by providing thermal energy to melt powders and fabricate the final near net shape part. AM process is capable to ,to fabricate complex shapes without the use of high tooling cost and at reduced material wastage which is well suited for high mix low volume part production. Selective Laser Melting (SLM) technique which falls under the gamut of AM techniques is a powder bed process where a high powered laser scans the powder to melt and solidify to a dense near net shape part [1].SLM has the ability to build complex designs, thin walled structures with density close to $99.9 \%$ of the theoretical density. However, the shortcoming of the process is the high power laser employed that can vaporize or destabilize the melt pool which causes surface roughness in the final part [2]. The high energy input also leads to large thermal gradients that give rise to internal stresses and microstructures with columnar grains which resulted in anisotropic properties. The mechanical properties of the as SLM printed IN625 samples have high strength but are low in ductility[3].Post heat treatment of the SLM printed parts could provide a workable solution to modify the microstructures and tailor the properties further to suit the application. This paper investigated on the mechanical properties and microstructures of as SLM printed IN625 samples before and heat treatment the mechanical properties and microstructures were also compared with the cast and wrought IN625 samples.

\section{Experimental Procedure}

The SLM250HL machine from SLM-Solutions was used to print rectangular bar shaped samples of size $(0.8 \mathrm{~cm}$ by $1.4 \mathrm{~cm}$ by $11 \mathrm{~cm})$ from IN625 powder. The process conditions employed were laser power of $360 \mathrm{~W}$, hatch spacing of $0.125 \mathrm{~mm}$ and at scan speed of $400 \mathrm{~mm} / \mathrm{s}$. Tensile coupons were machined from the bar shaped samples as per ASTM E8 standard as shown in Fig 1. Heat treatments of tensile coupons were done in a vacuum furnace (Thermal Technology LLC) which can reach $1300^{\circ} \mathrm{C}$ and vacuum level of $10^{-5}$ bar. Microhardness was recorded using Vickers hardness (HV) with $200 \mathrm{gf}$ load. For microstructure observation the samples were polished and electro-etched using 70\% phosphoric acid with settings of $5 \mathrm{~V}$ and 40 s.Images were taken in optical microscope and FE-SEM equipped with Energy Dispersive Spectroscopy(EDS) for analysis.

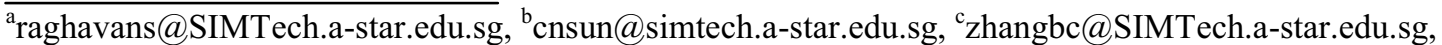

dsinwj@SIMTech.a-star.edu.sg, ${ }^{\mathrm{e}}$ wangp@imre.a-star.edu.sg, ${ }^{\mathrm{f}} \mathrm{mlnai} @$ simtech.a-star.edu.sg, ${ }^{\mathrm{g}} \mathrm{tli} @$ simtech.a-star.edu.sg,

hwei@simtech.a-star.edu.sg
} 


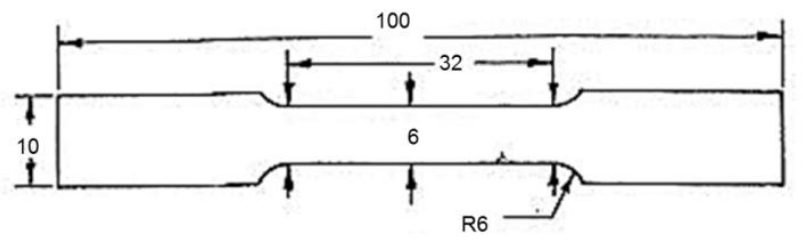

Fig 1.Tensile coupon as per ASTM E8 standard, units in mm.

\section{Results and Discussion}

The microstructures of as printed IN625 samples have long columnar grains along the build direction as seen in Fig 2, and the build layers formed horizontal to build direction are also visible after etching of the samples. Very fine dendritic structures of the order of 0.6-0.7 $\mu \mathrm{m}$ spacing are observed in Fig 2(b)with few dendrites displaying epitaxial growth across the build layers. The growth orientations of the dendrites are mainly along the build direction and perpendicular to build direction as observed in Fig 2(b). The carbides mainly precipitated along the grain boundary as seen in Fig 2(b), and this was also confirmed after EDS analysis.

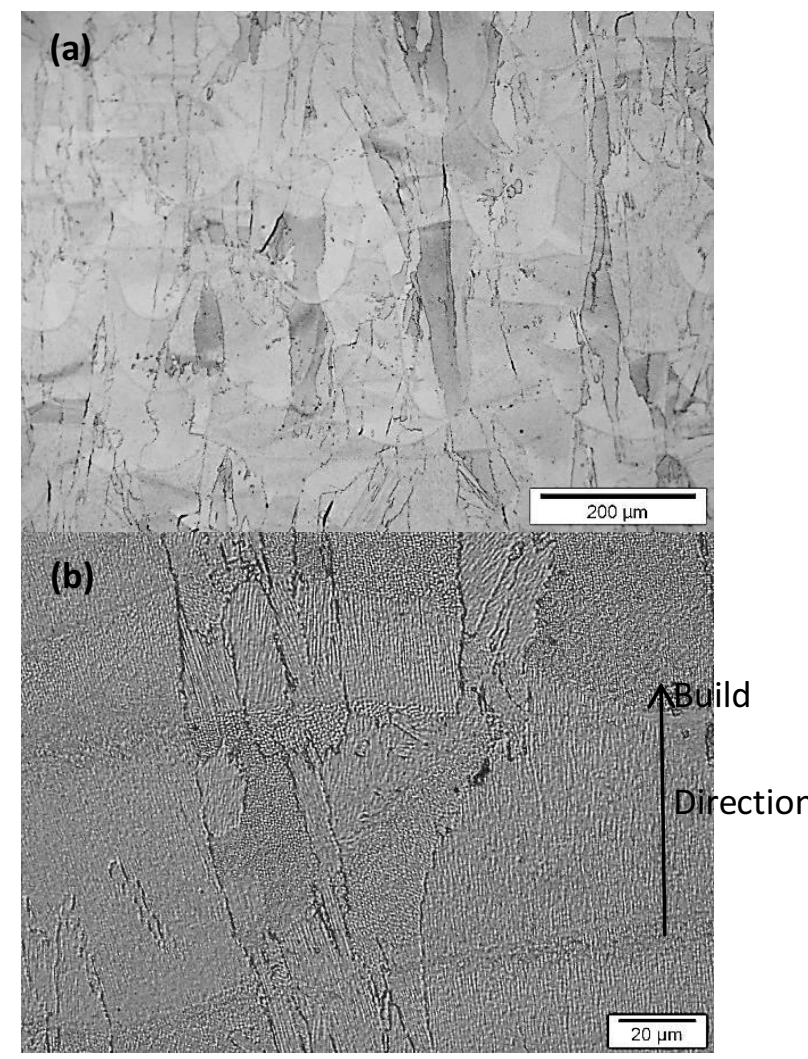

Fig 2.The SLM printed microstructures of IN625 revealing(a) grains at lower magnification and (b) fine dendrites at higher magnification.

Tensile tests were carried out for two batches of tensile coupons, one batch in the as printed condition and the other batch after heat treatment condition. The heat treatment temperature-time cycle given to the tensile coupons is shown in Fig 3a, which involved solutionizingat $1040^{\circ} \mathrm{C}$ for $2 \mathrm{~h}$ followed by fast cooling at $15^{\circ} \mathrm{C} / \mathrm{min}$ to $720^{\circ} \mathrm{C}$, ageing at $720^{\circ} \mathrm{C}$ for $7 \mathrm{hrs}$ and a secondary ageing at $650^{\circ} \mathrm{C}$ for $8 \mathrm{hrs}$. The main motivation of choosing this heat treatment cycle was to avoid laves phase and the orthorhombic phase in the alloy in which these phases would lead to embrittlement. The subsequent ageing processes was to promote the formation of fine precipitates of the hardening phase" to achieve higher strength properties in the alloy. Fig $3 \mathrm{~b}$ shows the microstructure after heat treatment, where the dendrites caused by segregation in the as printed structure has to large extent vanished and only grain boundaries are visible after etching.

The tensile and the microhardness results for the as printed and the heat treated samples are shown in Table 1. The SLM as printed samples exhibit good overall strength with yield and ultimate tensile strength however with lower ductility as compared to wrought and annealed IN625 properties [4].After heat treatment, the heat treated samples show a significant increase in ductility with a slight drop in UTS as compared to as printed samples. The mechanical properties of heat treated samples in general fall within the range of the wrought properties reported [4] and with higher ductility as compared to the as printed samples. . The main reason for low ductility in the as-printed samples could be due to the presence of brittle phases laves phase and phase [5] and the high internal thermal stresses generated in the alloy during the SLM process. The hardness value of both the as printed and heat treated samples compare well with the wrought IN625 hardness values.

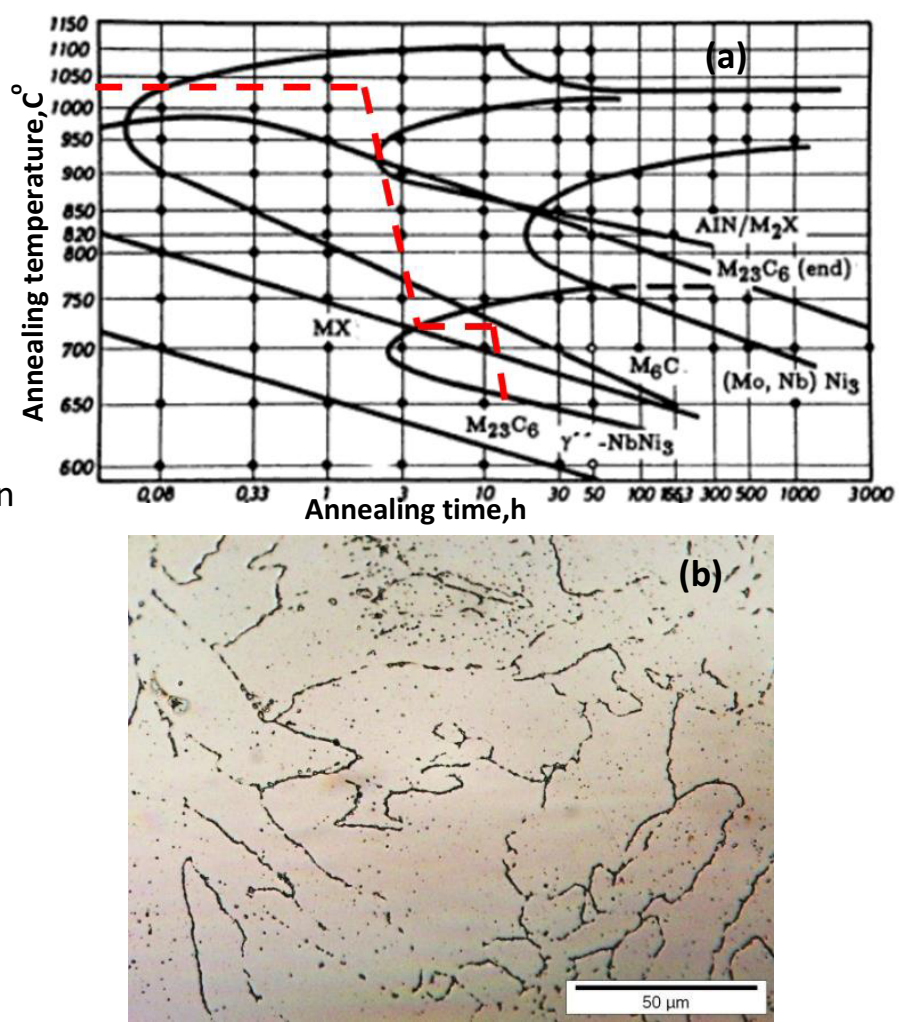

Fig 3.(a)Heat treatment cycle imposed on the TTT diagram[6](b) heat treated microstructure 
Table 1Tensile and microhardness results of SLM printed and heat treated samples compared with wrought IN625 [4].

\begin{tabular}{cccc}
\hline & As Printed & Heat Treated & Wrought and Annealed IN625[4] \\
\hline YS(MPa) & $641.5 \pm 23.5$ & $432.3 \pm 13.3$ & $414-655$ \\
UTS(MPa) & $878.5 \pm 1.5$ & $836.3 \pm 13.1$ & $827-1034$ \\
El (\%) & $30 \pm 2$ & $47 \pm 1.4$ & $30-60$ \\
Hardness(HV) & $289.0 \pm 14.5$ & $264.5 \pm 12.5$ & $150-300$ \\
\hline
\end{tabular}

The fracture surface of the as printed and the heat treated samples were observed under SEM after the tensile testing and the micrographs are shown in Fig 4(a) and (b) respectively. In Fig 4(a), the long straight striations feature could be observed in the fracture surface of the as printed sample. This fracture morphology could be likely representative of cleavage planes alongside with dimples and microvoids in the facture surface as seen in the micrograph. The presence of both dimples and cleavage planes may signify the mixed form of failure behaviour (ductile+brittle) in the as printed samples. In Fig 4(b), the fracture surface of heat treated samples revealed mainly dimple shaped features and microvoids indicating a more ductile fracture behaviour which explains for the higher ductility.

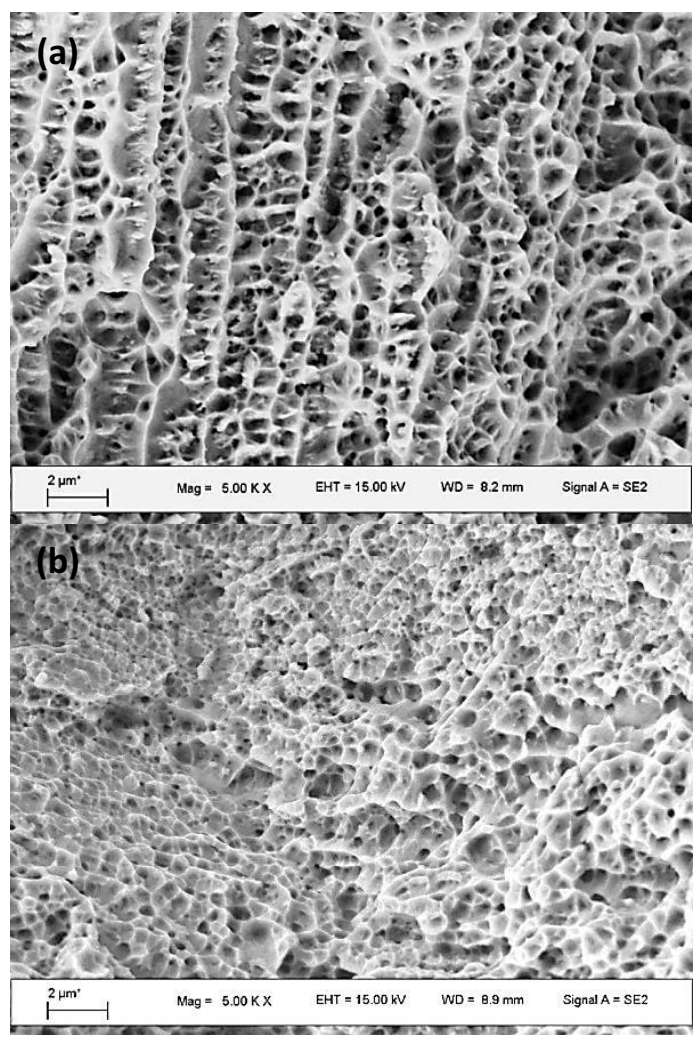

Fig 4.Fracture surface of (a) as SLM printed and (b) heat treated samples.

It is clear that with preliminary heat treatment studies, the mechanical properties can be altered significantly. Several other heat treatment cycles will be conducted inthe future research to capture the range of microstructures and the associated mechanical properties that can be obtained from the as printed SLM samples.

\section{Conclusions}

The following conclusions can be drawn from the current study.

1. The SLM as printed samples reveal very fine dendritic structure with columnar grains growing through multiple layers along build direction. After heat treatment, the SLM as printed samples show less dendritic segregation in the microstructure.

2. Tensile tests reveal that, the as printed samples exhibit good strength with average values of tensile strength of $879 \mathrm{MPa}$, yield strength of $642 \mathrm{MPa}$ but with lower elongation at $30 \%$. After heat treatment, elongation increased significantly to $47 \%$, with tensile strength and yield strength reduced marginally at $836 \mathrm{MPa}$ and $433 \mathrm{MPa}$.

3. The fracture surface of the heat treated samples show dimples and microvoids which indicate ductile fracture behaviour. The as printed sample fracture surface has a mixed fracture mode because of the presence of dimples and cleavage planes.

\section{References}

1. E.C.Santos, K.Osakada, M.Shiomi, Y.Kitamura, F.Abe: Journal of Mechanical Engineering Science,Vol 218, No. 7(2004), p. 711

2. K.A.Mumtaz, N. Hopkinson: Journal of Materials Processing and Technology, Vol 210 (2010), p. 210

3. I. Yadroitsev, L. Thivillon, Ph. Bertrand, I. Smurov: Applied Surface Science, Vol 254 (2007), p. 980.

4. Information from http://www.specialmetals.com

5. K. N. Amato, J. Hernandez, L. E. Murr, E. Martinez, S. M. Gaytan, P. W. Shindo: Journal of Materials Science Research. Vol 1, No.2, (2012), p. 3

6. Harry Chandler: Heat Treater's Guide: Practices and Procedures for Nonferrous Alloys. ASM International. 1996 